\title{
Breves apontamentos sobre a proteção social a refugiados venezuelanos no contexto brasileiro
}

\author{
Brief notes on social protection for Venezuelan refugees in the \\ Brazilian context
}

\section{Ariane Rego de Paiva \\ arianerpaiva77@hotmail.com}

Possui graduação em Serviço Social UFRJ, Mestrado e Doutorado pelo Programa de Estudos Pós-Graduados em Política Social pela UFF. Atualmente é Professora do Departamento de Serviço Social da PUCRio e do Programa de Pós-Graduação em Serviço Social da PUC - Rio.

\section{Ana Gabriela de Paiva Gonçalves agpaiva24@gmail.com}

Graduanda em Serviço Social pela PUC-Rio. Bolsista de Iniciação Cientifica pelo CNPQ no Grupo de Pesquisa Estado, Sociedade, Políticas e Direitos Sociais - GESPD/PUCRio.

\begin{abstract}
Resumo
O objetivo principal deste trabalho é analisar a relação entre as instituições públicas estatais e instituições privadas, na política de atendimento à população migrante e refugiada venezuelana. Os procedimentos metodológicos foram: revisão bibliográfica e documental, além da realização de entrevistas com os representantes do Poder Público no Estado de Roraima, durante visita técnica da Cátedra Sérgio Vieira de Mello da PUC-Rio em 2018.

Palavras-chave: refúgio; venezuelanos; proteção social; políticas públicas; integração. local.
\end{abstract}

\begin{abstract}
The main objective is to analyze the relationship between state public institutions and private institutions, in the policy of attending the Venezuelan migrant and refugee population. The methodological procedures were bibliographic and documentary review, besides conducting interviews with representatives of the public power in the state of Roraima, during a technical visit of the Sergio Vieira de Mello chair of PUC-Rio in 2018.
\end{abstract}

Keywords: refuge; Venezuelans; social protection; public policies; local integration. 


\section{Introdução}

O desenvolvimento capitalista e o acirramento da pobreza de grandes parcelas populacionais implicam em fluxos migratórios mais complexos. As "novas guerras" por disputas econômicas e políticas no cenário internacional e os eventos climáticos associados às questões socioeconômicas contribuem para migrações forçadas, devido à violação de direitos humanos. O Brasil é signatário dos principais tratados internacionais de direitos humanos, o que inclui sua participação na defesa internacional de migrantes e refugiados. Segundo o relatório Tendências Globais, do Alto Comissariado das Nações Unidas para os Refugiados (ACNUR) em 2018, foram 70,8 milhões de pessoas deslocadas de forma forçada no mundo. Destes, 25,9 milhões eram considerados refugiados, por estarem fugindo de conflitos, guerras e perseguições; 3,5 milhões eram solicitantes de refúgio; e 41,3 milhões eram considerados deslocados internos, ou seja, que não cruzaram a fronteira de seus países.

Devido aos fluxos migratórios de cidadãos venezuelanos em direção ao Brasil, em decorrência da crise política, econômica e social pela qual atravessa a Venezuela, o estudo que aqui será apresentado tem como objeto de análise a proteção social desempenhada pelo Estado brasileiro aos venezuelanos que solicitaram refúgio no país. Esta temática tem sido amplamente discutida nos mais diversos espaços da sociedade, como em mídias eletrônicas, canais de informação e produção de conhecimento (a universidade) etc. A temática do refúgio no contexto brasileiro é tida por alguns intelectuais "como algo novo", o que requer pensar respostas do Estado brasileiro na garantia dos direitos dos refugiados.

Inicialmente, foi proposta uma pesquisa que abordasse a temática da infância migrante na região metropolitana do estado do Rio de Janeiro. Porém, em setembro de 2018, tivemos a oportunidade de visitar o estado de Roraima, em missão da Cátedra Sérgio Vieira de Mello da PUC-Rio junto ao ACNUR. Com isso, adquirimos conhecimento sobre a realidade do atendimento aos refugiados venezuelanos na região de fronteira. O projeto foi então ampliado para a compreensão da nova realidade do fluxo migratório que tem chegado à região metropolitana do Rio de Janeiro pelo "projeto de interiorização" do governo federal, além de permanecer com o objetivo de identificar a situação de crianças e adolescentes venezuelanas no processo de interiorização e seu acesso à assistência social.

O cenário atual do Brasil é de poucos investimentos políticos e econômico-financeiros neste tema, o que requer pensar o papel do Estado brasileiro no estágio do desenvolvimento capitalista mundial, seu pacto federativo e como vêm se desenvolvendo a descentralização e o 
cofinanciamento das ações nos diferentes níveis de governo. Outra justificativa para empreender este estudo é contribuir com o levantamento de programas e serviços públicos e privados acessados pela população refugiada, em especial a venezuelana, como parte da proteção de direitos humanos no Brasil e apresentar seus impasses para melhorar as políticas existentes, ou mesmo influenciar a formulação de novas ações.

\section{Percurso metodológico}

Esta pesquisa possui caráter qualitativo, para sua efetivação realizamos levantamento bibliográfico (teses, monografias e artigos publicados sobre o tema) e análise documental (normativas da esfera nacional e estadual), com vistas a proporcionar maior aproximação com o objeto pesquisado e estabelecer um quadro preliminar sobre a política nacional e estadual para migrantes e refugiados. Afinal, como destaca MINAYO (2011), temos de nos aprofundar nas obras dos diferentes autores que trabalham os temas que nos preocupam. Inclusive dos que trazem proposições com as quais ideologicamente não concordamos.

Delimitou-se como objetivos dessa pesquisa ampliada: 1) conhecer as possíveis contradições e entraves na garantia de direitos e de proteção social de crianças e adolescentes na condição migratória, ou as de seus pais/responsáveis; 2) analisar a relação entre as instituições públicas estatais e instituições privadas na política de atendimento à população migrante e refugiada; 3) Conhecer as formas de acesso das famílias em fluxo migratório aos serviços e benefícios das políticas públicas, com atenção especial às crianças e adolescentes. Este trabalho foi recortado no segundo objetivo, relacionado ao processo de recepção dos venezuelanos em Roraima.

Foram realizadas cinco entrevistas, com representantes da força tarefa do governo federal na Operação Acolhida, dos governos municipal e estadual em Roraima, da Universidade Federal de Roraima e da Polícia Federal (essa sem autorização para gravação) em setembro de 2018, além da observação sobre o funcionamento dos abrigos construídos na fronteira para acolhimento dos venezuelanos em Boa Vista e Pacaraima. As entrevistas foram transcritas e analisadas com participação de uma aluna de pesquisa de iniciação científica.

Concomitante às atividades de análise das entrevistas, a aluna participou do Grupo de Estudos CSVM-PUC-Rio realizado durante os meses de março, abril, maio e junho de 2019, como estratégia para a condução deste estudo, pois permitiu uma troca de conhecimento com 
diferentes áreas de conhecimento. O segundo momento dessa pesquisa trará entrevistas realizadas na Região Metropolitana do estado do Rio de Janeiro.

\section{Refúgio: um conceito em disputa}

As políticas migratórias exigem efetiva acolhida e inserção na comunidade nacional (IMDH, 2014). A política nacional para migrantes e refugiados combina elementos da política externa e da política interna (MOREIRA, 2010). A genealogia do refúgio, no século XX, demonstra que esse conceito passou por uma constante evolução, com o objetivo de se adequar às novas requisições e imposições do ordenamento sócio demográfico colocados pelo modo de produção capitalista.

Alguns autores vão atrelar o surgimento da categoria refúgio aos acontecimentos advindos da I Guerra Mundial (1914-1918), que aconteceu no cenário europeu e deixou mais de dez milhões de pessoas mortas. Posteriormente, em 1930, a ascensão do nazismo ocasionou a morte de mais de seis milhões de pessoas em campos de concentração - o holocausto. Esse período é retratado no livro As Origens do Totalitarismo escrito por Hannah Arendt, filósofa alemã e judia, que teve que pedir refúgio em decorrência dessa forma perversa de governabilidade que vigorou na Alemanha. No livro, a autora analisa o surgimento de estruturas de poder (os governos totalitaristas) voltadas para uma forma total de dominação, que não se detêm nem mesmo diante da tarefa monstruosa de eliminar populações inteiras, para fazer triunfar ideias abstratas e crenças na superioridade de raças e de ideologias.

Com o advento da II Guerra Mundial, em 1940, as mudanças no perfil das guerras, o aumento das crises políticas, as ações temporárias tomadas pelos organismos internacionais de proteção social aos indivíduos devido a migrações forçadas foram fatores que levaram à criação do Alto Comissariado das Nações Unidas para Refugiados (ACNUR) em 1950. O fundamento legal que está nos pilares do trabalho desenvolvido pelo ACNUR é a Convenção de 1951, que dispõe sobre o Estatuto dos Refugiados em âmbito internacional, e estabelece os direitos e deveres entre os refugiados e os países que os acolhem. A partir desses acontecimentos históricos, estabeleceu-se que os refugiados são:

Pessoas que estão fora de seu país de origem devido a fundados temores de perseguição relacionados a questão de raça, religião, nacionalidade, pertencimento a um determinado grupo social ou opinião política, como 
também devido à grave e generalizada violação de direitos humanos e conflitos armados. (ACNUR, Convenção de 1951)

O sistema de proteção aos refugiados vem sendo construído gradualmente, conforme o processo sócio-histórico do desenvolvimento capitalista, e principalmente, gira em torno dos acontecimentos violentos que colocam milhões de indivíduos sob risco de perseguição e/ou de intolerância. Portanto, ficamos com as palavras de Moulin (2012), que ao apresentar as divergências em torno da figura do refugiado e do migrante, evidencia que:

\footnotetext{
O refugiado é produto de um sistema internacional que se origina, reage e se reproduz enquanto resposta ao medo de um ataque potencial. O refugiado é um sintoma de uma estrutura internacional organizada ao redor do medo patológico da morte iminente representada pela presença do outro e de uma condição anárquica. (2012, p.7).
}

Esse sistema internacional é um campo de disputas ideológicas, alimentado por interesses antagônicos, também é o mesmo que oculta que estamos diante de pessoas que migram (GOMARASCA, 2017, p.18), reforçando o imaginário social construído em torno dessas pessoas como terroristas ou criminosos. Não à toa, a ordem jurídica estabelecida socialmente, diferencia refugiados e migrantes, atribuindo uma série de nomenclaturas em torno dessas pessoas. Ao falar dessas categorias de indivíduos, é necessário que haja uma análise sistêmica da ordem internacional e do seu funcionamento jurídico, não podemos pensar essas categorias individualizadas, pois a produção do significado se dá no sistema como um todo.

Essas inúmeras categorias (migrantes econômicos, refugiados, refugiados ambientais etc) são novas formas de designar quem são os "estrangeiros", é um fracionamento do rótulo para poder gerir as populações. Um questionamento que deve andar alinhado com essas análises, diante desse contexto, é: qual seria a responsabilidade da política internacional e dos Estados, que se encontram no dilema ético entre o direito de excluir e o direito de acolher? (GOMARASCA, 2017). Deve-se levar em consideração que, nos últimos anos, a população mundial passou a vivenciar uma maior intensidade em seus deslocamentos nos territórios e as trajetórias tornaram-se mais complexas em termos de composição, distância e, sobretudo, no que se refere às suas causas e consequências (ZAPATA; GUEDES, 2017).

\section{As políticas migratórias brasileiras em questão}

No Brasil, o período de redemocratização foi um importante marco para novas formas de organização e regulamentação da política para migrantes e refugiados. A questão entrou no DIGNIDADE RE-VISTA | ISSN2525-698X| 2018 | V. IV | N. 8 | Políticas Públicas e Direitos Humanos. Pastoral Universitária Anchieta PUC-RIO. 
debate nacional atrelada ao tema dos direitos humanos, em destaque na cena internacional. Isso se deveu não só a interesses defendidos pelo novo governo, mas também às instituições religiosas que tiveram atuação importante na fase de transição do fim do regime militar e o percurso em prol da recuperação da democracia. Também foi relevante a participação da agência da Organização das Nações Unidas (ONU) nesse processo (MOREIRA, 2010, p.117).

Cabe ressaltar que a implementação das políticas migratórias brasileiras acompanham o cenário político internacional, em que os fluxos migratórios são reorientados pelas demandas do capital de modo geral. Eduardo Galeano, escritor e jornalista uruguaio, estava certo ao afirmar que o desenvolvimento é uma viagem com mais náufragos do que navegantes. Portanto, ao estudar os fluxos migratórios numa perspectiva da análise da totalidade, e suas características afiançadas no modo de produção capitalista, podemos afirmar que a migração não possui uma única definição, pois é um fenômeno com múltiplas expressões espaciais e temporais.

Resgatar o processo histórico de formação politicoeconômica dos países latinoamericanos, mesmo que brevemente, é um passo importante para a compreensão dos fluxos migratórios desencadeados pela crise do capital e seus rebatimentos na América Latina, que continua sendo fonte de exploração das principais potências mundiais - desde 1800, no contexto das colônias inglesas, através da exploração do açúcar de Cuba, do café do Brasil, de couro do Rio da Prata, ou do guano e do nitrato do Peru (GALEANO, 2000, p.166). Ainda hoje, os países latino-americanos são explorados através dos mecanismos atuais de espoliação do processo de acumulação capitalista. Importante salientar que, no âmbito da América Latina, o conceito de refúgio foi ampliado a partir da Declaração de Cartagena em 1984,

Que contemplou como refugiado a pessoa que tenha fugido do seu país por terem sido ameaçadas pela violência generalizada. Esta Declaração, embora não tenha força normativa, foi mais um instrumento de proteção internacional aos refugiados, sendo elaborada em decorrência das guerras que ocorreram em alguns países da América Central nos anos de 1970 e 1980. (SILVA; PAIVA, 2018, p.2)

Harvey (2013) indica que as mudanças do regime de "acumulação flexível” (em contraponto ao regime rígido do fordismo) a partir da década de 1970 estão associadas a um novo sistema de regulamentação política e social, que também impacta novas formas de controle do trabalho e do emprego. Para o autor, novos grupos de imigrantes nas grandes cidades podem significar "coisas bem diferentes em diferentes lugares". Podem significar novas estratégias de sobrevivência para desempregados ou pessoas que vivenciam situações de 
discriminações, bem como podem existir apenas grupos de imigrantes tentando entrar em um sistema capitalista. Sendo assim,

O mundo após o fim da guerra fria, assiste a uma multiplicação de conflitos regionais fortemente geradores de deslocamentos forçados, quer os de natureza claramente política, como no caso da perseguição por razões étnicas ou religiosas, quer os de natureza econômica, mas associada também a conflitos e discriminação. (NETO, 2008, p.396)

Na década de 1990, o governo de Fernando Henrique Cardoso (1996-2002) deu início ao processo de institucionalidade à política de migração atrelada aos Direitos Humanos, com a elaboração do Primeiro Programa Nacional de Direitos Humanos - PNDH I, de 1996, a criação da Secretaria Nacional de Direitos Humanos em 1997, e a aprovação da Lei 9.474, de 22 de julho de 1997 (Lei do Refúgio). A Lei instituiu o Comitê Nacional para Refugiados - CONARE, que possui representação do ACNUR, de órgãos do governo federal e de representantes da sociedade civil.

O Governo Lula (2003-2010) aprofundou e consolidou a institucionalização das ações aos refugiados, com expectativas do Estado brasileiro assumir uma posição diferenciada na região da América Latina diante das relações internacionais. Para integração dos refugiados e migrantes no país de acolhimento há um processo complexo que abrange aspectos socioeconômicos e culturais, que envolve inserção no trabalho e condições de moradia, o aprendizado da língua, a utilização de serviços públicos e a construção de relações sociais com membros da comunidade local (AGER; STRANG, 2008 apud MOREIRA, 2010).

No Brasil, não existe uma aproximação entre o governo federal e os outros entes de forma continuada e satisfatória para sensibilizar os órgãos públicos para a situação dos migrantes e dos refugiados, com uma ausência clara de política afirmativa para integração local deste público. Além disso, a população migrante e refugiada não tem sido incluída nos espaços decisórios para a formulação de ações específicas para atender suas demandas. São as organizações não governamentais que historicamente vêm destinando atendimentos para estes segmentos. No caso dos reassentados, há uma assistência maior, já que o ACNUR e o governo brasileiro destinam verbas às Cáritas e seus parceiros, que provêm ajuda de subsistência, moradia e curso de português aos refugiados e os auxilia na busca de emprego. Porém, após dez anos de implementação do programa de reassentamento, os desafios permanecem, sobretudo em relação à autossuficiência dos refugiados. 
Refúgio não é um tema que deve ser apenas tratado dentro do direito internacional, fugir, em determinados contextos, é ter o direito de sobreviver. O fundamento legal do "status de refugiado" deveria declarar que o refugiado não tem condições de permanecer no seu país e por isso precisou recorrer à legislação internacional. No entanto, o que temos visto é que até mesmo em momentos em que esse status é deferido poucas são as opções de regularização migratória e a qualquer momento esse reconhecimento pode ser retirado, ou seja, não garante estabilidade.

A vinda de migrantes ao Brasil era regulamentada até pouco tempo pelo Estatuto do Estrangeiro (Lei 6.815/1980). Fruto do período da ditadura militar, essa lei era responsável pelo tratamento destinado às questões dos migrantes no território nacional. A aplicação dessa legislação deveria atender precipuamente à segurança nacional, à organização institucional, aos interesses políticos, socioeconômicos e culturais do Brasil, bem como à defesa do trabalhador nacional. Além de utilizar a nomenclatura "estrangeiro" para se referir aos imigrantes, Silva e Paiva (2018) destacam que essa legislação denotava cunho preconceituoso e xenofóbico e não promovia a proteção devida a migrantes não documentados ou irregulares no país, conforme estabelecem os padrões internacionais, aumentando ainda mais as situações de vulnerabilidade de certos grupos de migrantes. Essa lei vigorou concomitante ao Estatuto do Refugiado, e já com os preceitos progressistas e democráticos da Constituição Federal de 1988.

Durante o Governo Temer, o Brasil recebe pela primeira vez o impacto de um deslocamento forçado e terrestre de refugiados venezuelanos em direção ao território brasileiro. Isso levou o governo a adotar novas medidas de proteção e regulamentação diante dos fluxos migratórios. O estado de Roraima virou manchete nos jornais nacionais. O estado de "crise humanitária" e o "colapso dos serviços públicos", anunciados por representantes do poder público da região, em decorrência da imigração de venezuelanos, legitimou uma série de intervenções tomadas pelo Governo Federal em conjunto com as forças nacionais, organizações internacionais e atores da sociedade civil.

Acerca das novas medidas de proteção e regulamentação dos fluxos migratórios, destacamos a aprovação da nova Lei de Migração (Lei 13.445) em 2017, que substituiu o Estatuto do Estrangeiro, com vistas a atender os princípios da defesa dos Direitos Humanos e os tratados internacionais dos quais o Brasil é signatário. A criação da Operação Acolhida, iniciada em meados de 2018, foi um instrumento de ação tomado pelo Estado brasileiro, como resposta ao fluxo de venezuelanos que ingressaram no país. Essa operação é designada como "força tarefa logística humanitária em Roraima", e envolve vários órgãos federais (Exército Brasileiro, Polícia Federal, Anvisa, Ministério do Desenvolvimento Social, Ministério de Direitos Humanos, Defensoria Pública da 
União), além de diversas agências internacionais (ACNUR, OIM, UNFPA, Unicef) na sua organização.

O espaço de atuação da Operação Acolhida se dá nos municípios de Pacaraima e Boa Vista, e tem como objetivo combater crimes fronteiriços e controlar os fluxos migratórios com apoio das Forças Armadas, que possuem um papel central na questão do atendimento e acolhimento dos refugiados. Foram criados treze abrigos em Roraima através da Operação Acolhida. Alguns autores vão apontar que a construção dos abrigos possui relação com a presença do grande fluxo de venezuelanos em situação de rua, nas principais vias da cidade e até mesmo em torno da rodoviária.

\begin{abstract}
A presença venezuelana pode ser notada nas ruas da cidade, seja pelos que vendem alguma coisa em cruzamentos de avenidas como forma de sobrevivência, seja por aqueles que se abrigam no fim do dia debaixo de uma árvore ou de alguma cobertura para passar a noite. Nos comércios da cidade, onde deles muitos trabalham, o sotaque hispânico é facilmente perceptível. Contudo são nos trezes abrigos espalhados pela cidade que grande parte dos venezuelanos se encontra alojada em Boa Vista. (SILVA, 2018, p.206)
\end{abstract}

Concomitante ao processo de construção dos abrigos, o "Processo de Interiorização" é um dos pilares da Operação Acolhida, que tem como principal objetivo oferecer abrigo e/ou oportunidades de geração de renda em outras regiões do país. As estratégias adotadas em torno da presença dos venezuelanos em RR dividem opiniões entre juristas, representantes dos poderes públicos e defensores dos direitos humanos. O relatório das violações de direitos contra imigrantes venezuelanos no Brasil, disponibilizado pelo Conselho Nacional dos Direitos Humanos (CNDH) em 2018, constatou alguns entraves no atendimento e no acolhimento dos migrantes: o primeiro ponto a ser destacado é a falta de coordenação de ações nos três níveis de governo - municipal, estadual e federal; o segundo é o baixo compartilhamento de informações oficiais sobre o fluxo migratório. Esses entraves apareceram nas entrevistas realizadas durante a visita técnica pela Cátedra Sérgio Vieira de Mello (CSVM) da PUC-Rio em 2018, e serão explorados mais à frente.

Após as eleições presidenciais em 2018, observa-se, no cenário sociopolítico brasileiro, discursos que ecoam em torno da "soberania nacional", marcados por uma ideologia de extrema direita excludente, seletiva e xenofóbica. A primeira semana do atual Governo Federal, além de promover uma série de modificações na estrutura dos Ministérios com base em decretos, no que tange às políticas públicas voltadas para a proteção social de refugiados e imigrantes, estabeleceu, pelo Decreto $N^{\circ}$ 9662/2019, que os assuntos em torno da Política Nacional de 
Migrações e Refugiados passaram a ser vinculados à Secretaria Nacional da Justiça e Segurança Pública.

Art. 15. Ao Departamento de Migrações compete:

I - estruturar, implementar e monitorar a Política Nacional de Migrações, Refúgio e Apatridia;

II - promover, em parceria com os órgãos da administração pública federal e com a sociedade civil, a disseminação e a consolidação de garantias e direitos dos migrantes e dos refugiados, nas áreas de sua competência;

III - atuar para a ampliação e a eficácia das políticas e dos serviços públicos destinados à prevenção da violação de garantias e à promoção dos direitos dos migrantes;

Após essa alteração, o Governo Federal comunicou a diplomatas da Organização das Nações Unidas (ONU) a retirada do Brasil do Pacto Global para a Migração da ONU.

\section{O refúgio no Brasil e suas características: aproximações iniciais}

Nos últimos anos, alguns estudos têm apontado os países da América Latina como opções adotadas para refúgio. Argentina, Brasil, Colômbia, Panamá, entre outros, tornaram-se o destino de milhares de pessoas que migram em função de acontecimentos de ordem política, social e econômica. Conforme Neto aponta em seus estudos, as áreas de destino para imigração, e mesmo as de passagem, vem, assistindo a tendências restritivas quanto à entrada, permanência e trânsito de migrantes, refugiados e solicitantes de asilo (2008, p.394).

A situação socioeconômica e política por que atravessa a Venezuela tem sido um dos principais fatores que levaram mais de 1,5 milhões de cidadãos venezuelanos a se deslocarem para os países vizinhos e outros mais distantes. No Brasil, o estado de Roraima, através da BR174, tem sido a principal rota de acesso ao território brasileiro por venezuelanos. Esta rodovia é a única que tem ligação com o resto do Brasil, a BR-174 atinge as principais cidades e conecta com todas as demais rodovias, sendo simultaneamente porta de entrada e porta de saída para produtos e pessoas.

O intenso fluxo migratório de venezuelanos para os países latino-americanos é a expressão mais forte e concreta da crise política, econômica e social que ocorre no país. Estamos frente a um fenômeno aparentemente inédito, uma vez que a Venezuela tem sido um país que historicamente tem recebido imigrantes e não ao contrário. Os movimentos de saída dos venezuelanos de seu país refletem, atualmente, umas das mobilidades urbanas mais intensas 
do mundo. Em termos estatísticos, a ACNUR aponta que entre 2014-2017 já se somaram mais de 22 mil solicitações de refúgio de venezuelanos no Brasil (FGV DAPP, 2018). Recorrendo aos estudos empreendidos por Vasconcelos (2018), em que a autora, ao apresentar alguns aspectos da migração venezuelana em Boa Vista (RR), relata que receber, enviar e compartilhar comida são os principais motivos que orientam o processo migratório.

A partir de uma visita técnica ao estado de Roraima (RR), pela Cátedra Sérgio Vieira de Mello (CSVM) da PUC-Rio em 2018, conseguimos realizar entrevistas com os representantes do poder público do estado, para obter informações referentes ao processo de chegada de migrantes e/ou refugiados no contexto brasileiro. Foram realizadas cinco entrevistas: com um representante da força tarefa do governo federal na Operação Acolhida, com dois representantes dos governos municipal e estadual em Roraima, um representante da Universidade Federal de Roraima e um representante da Polícia Federal (essa sem autorização para gravação) em setembro de 2018, além da observação sobre o funcionamento dos abrigos construídos na fronteira para acolhimento dos venezuelanos em Boa Vista e Pacaraima.

Com relação ao processo de chegada dos venezuelanos, as entrevistas revelam que o fluxo começou a se intensificar a partir de 2016, com a presença de índios da tribo venezuelana Waraó. Cabe ressaltar, que o fluxo de entrada e saída dessas pessoas varia de acordo com os acontecimentos da Venezuela.

Mas a partir de 2015, você começa a perceber um fluxo de pessoas muito no comércio. Eram pessoas que vinham para cá para fazer compras, então você via algumas caminhonetes lá da Venezuela vindo e comprando mantimentos e voltando. Algumas na farmácia comprando produtos de higiene pessoal, mas era compra e retorno. Um movimento pendular. (Entrevista. Representante da UFRR.)

Então você tem essa chegada e a partir de 2017 é mais evidente o número de vulneráveis um pouco maior, você vê mais gente em situação de rua, mais gente com uma condição de saúde mais debilitada. Por exemplo, essas pessoas chegavam muitas vezes com carro (2015-2016), já no final de 2016 você já consegue perceber a presença dessas pessoas numa condição mais complicada, a gente consegue acompanhar o declínio da economia venezuelana principalmente no acesso a alimentos e medicamentos, que impacta na chegada dessas pessoas. (Entrevista. Representante da UFRR)

Um assunto novo que demandava respostas imediatas. E quais seriam as respostas dadas pelas autoridades brasileiras em relação ao assunto? A criação de um plano de emergência anunciado pelo Governo Federal em 2018 reforçou a necessidade da articulação entre os três 
poderes governamentais e órgãos internacionais. Posteriormente, a presença da Polícia Federal e do Exército brasileiro no controle intensivo das fronteiras, e a criação de abrigos próximo às fronteiras foi a maneira encontrada para "o Governo Federal e o Brasil assumirem que é um problema de todos nós" (Entrevista. Representante da Prefeitura de Boa Vista). Ainda que essas atitudes sejam uma parte muito importante do processo, no entanto, os desafios com relação à integração dos migrantes na sociedade brasileira ainda permanecem.

Evidentemente, todas as entrevistas realizadas apontam para uma sobrecarga dos serviços públicos no estado de RR. A ausência de verbas destinadas às políticas que integram as políticas da seguridade social, o esgotamento de remédios, das vagas escolares, a superlotação das unidades hospitalares e a criação de abrigos como respostas de "acolhimento" trazem à tona as contradições em torno das políticas migratórias adotadas pelo estado brasileiro.

Devido os fluxos migratórios, e a permanência de venezuelanos em Roraima, o processo de interiorização, nas palavras do representante da força tarefa do governo federal na Operação Acolhida: “é um objetivo a ser perseguido". Esse “objetivo" em tese, oferece possibilidades para os venezuelanos migrarem para outras regiões do Brasil. Um estudo empreendido pela Cátedra Sérgio Vieira/UFRR, acerca do perfil sociodemográfico da migração venezuelana no Brasil, aponta que a principal razão para aceitação do deslocamento para outras regiões do país (caso haja apoio do governo brasileiro) é a possibilidade de emprego $(79,6 \%)$, seguida de ajuda econômica $(11,2 \%)$ e ajuda com moradia $(5,2 \%)$.

Para efetivação da política de interiorização, é necessária uma articulação em conjunto entre os governos, responsáveis pela garantia dos direitos sociais, políticos, civis e econômicos da população. No entanto, o que se observa é uma resposta militarizada, dada pelo Estado brasileiro, para o gerenciamento da questão migratória, em que as forças armadas assumiram o papel principal da política.

Na minha avaliação do que eu estou vivendo aqui, é reforçar a interiorização, é dividir para o resto do Brasil esse problema. (Entrevista. Representante do governo municipal de Boa Vista)

Por conta da situação venezuelana para alguns e não são poucos, permanecer junto à fronteira é um fator fundamental. (Entrevista. Representante da UFRR)

As frases citadas acima reforçam a necessidade de pensar estratégias que levem em consideração a condição particular dos venezuelanos e a realidade que o estado de RR tem enfrentado. A interiorização se tornou a única política aceitável quando há imigrantes que 
precisam permanecer na fronteira para manter contato com a família, o que não considera a diversidade dos imigrantes que adentram o país.

\section{Considerações finais}

Este estudo buscou apresentar dados referentes às políticas adotadas pelo Estado brasileiro em Roraima, como respostas aos fluxos migratórios desencadeados pela população venezuelana. Verificamos, nesse contexto, a presença das Forças Armadas no tocante à implementação e gestão da Operação Acolhida, entre tantos outros entraves que perpassam a lógica do atendimento aos refugiados. No cenário mundial, estamos diante de um dilema ético entre acolher ou excluir migrantes e refugiados. Portanto, os estudos voltados para análise das migrações em qualquer contexto que seja são de suma importância para viabilização de novas estratégias em defesa dos direitos humanos. Direitos que têm sido constantemente violados, apesar dos tratados internacionais serem assinados por diversas nações. Nesse contexto é importante reafirmar que: migrar é um direito humano!

Por fim, e não menos importante, o discurso de ódio contra refugiados e migrantes vem sendo adotado como política de enfrentamento à questão migratória por diversos países e com forte apoio populacional. No cenário global, o mundo está acompanhando a criação de Centros de Detenção na fronteira do Texas para imigrantes que entram nos Estados Unidos a partir do México, resultantes das políticas de "tolerância zero" adotadas pelo governo norte-americano. A prisão de Carola Rackete, capitã alemã da Sea-Watch, responsável pelo resgate de 42 imigrantes em Lampedusa, na Itália, é outro exemplo das políticas de restrição severa à mobilidade de migrantes, ou mesmo de seu encarceramento em certas condições. A crescente associação entre criminalidade, terrorismo e a mobilidade "não autorizada" são elementos que ajudam a entender, nas últimas décadas, o novo contexto de fechamento dos estados à migração (NETO, 2008, p.395). 


\section{Referências bibliográficas}

ACNUDH. Convenção Internacional sobre a Proteção dos Direitos de Todos os Trabalhadores Migrantes e dos Membros das suas Famílias, 1990.

ACNUR. Declaração de Cartagena, 1984.

BRASIL. Constituição Federal da República, 1988.

Decreto no 9. 662, de $1^{\text {o }}$ de janeiro de 2019. Disponível em: <http://www.planalto.gov.br/ccivil_03/_Ato2019-2022/2019/Decreto/D9662.htm>. Acesso em: 9 jul 2019.

FGV DAPP. Desafio migratório em Roraima: repensando a política e gestão da migração no Brasil. Rio de Janeiro, 2018.

GALEANO, Eduardo. As veias abertas da América Latina. Trad. Galeno de Freitas. 39.ed. Rio de Janeiro: Paz e Terra, 2000,

GOMARASCA, Paolo. Direito de excluir ou dever de acolher? A migração forçada como questão ética. REMHU, v.XXV, n.50, p.11-24, ago 2017.

HARVEY, David. Condição Pós-Moderna. 24.ed. São Paulo: Ed. Loyola, 2013.

IMDH. Cadernos de Debates Refúgio, Migrações e Cidadania. v.IX, n.9. Brasília: Instituto Migrações e Direitos Humanos, 2014.

MINAYO, Maria Cecilia de Souza (Org.). Pesquisa Social: Teoria, Método e Criatividade. 22.ed. Petrópolis: Vozes, 2003.

MOREIRA, Julia Bertino. Redemocratização e direitos humanos: a política para refugiados no Brasil. Revista Brasileira de Política Internacional. v.LIII, n.1, p.111-129, 2010.

MOULIN, Carolina. A política internacional da mobilidade: governamentalidade global e a produção da diferença no discurso disciplinar contemporâneo. Migrações e a Pan-Amazônia. Manaus: Editora UFAM. 2012.

NETO, Helion Póvoa. O Erguimento de barreiras à migração e a diferenciação dos direitos à mobilidade. REMHU, v.XVI, n.31, 2008.

SILVA, Mary Cristina; PAIVA, Ariane. Proteção social à infância migrante na região metropolitana do estado do Rio de Janeiro. Relatório de Pesquisa, Rio de Janeiro: PUC-Rio, 2018.

SILVA, Sidney. Políticas de abrigamento a imigrantes venezuelanos em Boa Vista e Manaus: algumas indagações. Campinas, 2018. Seção: Fronteira Norte, Acolhimento e Xenofobia. Disponível em: <https://www.nepo.unicamp.br/publicacoes/livros/mig_venezuelanas/ migracoes_venezuelanas.pdf $>$. Acesso em: 29 jul 2018. 
ZAPATA, Gisela; GUEDES, Gilvan. Refúgio e modalidades de deslocamentos populacionais no século XXI: tendências, conflitos e políticas. Rev. bras. Estud. Popul, v. XXXIV, n.1, p.513, 2017. 